\title{
Downstream Activities at the Felda Land Development Scheme: Analysis on Motivational Factors of Women's Participation in Business Activities
}

\author{
Idris, N.A.H. ${ }^{1}$, Salleh, N.H.M. ${ }^{1} \&$ Endut, W. ${ }^{1}$ \\ ${ }^{1}$ School of Economics, Faculty of Economics and Management, Universiti Kebangsaan Malaysia, Bangi \\ Selangor, Malaysia \\ Correspondence: Salleh, N.H.M., School of Economics, Faculty of Economics and Management, Universiti \\ Kebangsaan Malaysia, Bangi Selangor, Malaysia. Tel: 60-13-315-3812. E-mail: norlidahanim@gmail.com
}

Received: May 15, 2014 Accepted: June 6, 2014 Online Published: July 11, 2014

doi:10.5539/ass.v10n15p143

URL: http://dx.doi.org/10.5539/ass.v10n15p143

\begin{abstract}
Federal Land Development Authority (FELDA) in Malaysia has been a successful land development agency for the past fifty-two years. Established on 1 July 1956, it is the main government instrument in reducing rural poverty in the Federation of Malaya. FELDA itself has grown into a conglomerate with numerous subsidiaries and joint-venture companies engaged in a variety of related upstream and downstream business. This paper deals with women's participation in downstream activities. It provides an analysis on the motivational factors that influence the participation of the said activities among women in land development scheme. The objective of the study is to analyse motivational factors that encourage women to get involve in business activities. The study is quite important because FELDA wanted the settlers, men or women, to do more than just managing their oil palm or rubber holding but they must also become entrepreneurs in order to diversify their source of income. A set of questionnaire had been used as a method for data collection and it was distributed to 292 respondents involved in the downstream activities. There were ten areas surveyed which include FELDA Raja Alias, FELDA Jengka, FELDA, FELDA Jelai, FELDA Chini, FELDA Palong, FELDA Pasak, FELDA Air Tawar, FELDA and FELDA Palong Timur, which are located in Malaysia. The data obtained were then analyzed by the Statistical Packages for the Social Science (SPSS) 21.0. This was conducted in order to obtain the frequency, percentage as well as factor analysis and the reliability tests of each item as well as the constructs. In addition, the study also employed SPSS AMOS version 5 for the evaluation of the relationship among the motivation items by using structural equation model. Besides that, the study using the Thematic Apperception Test (TAT) in looking personality traits that posses by women entrepreneurs. In general the findings showed that 'the desire for success' as the most important factor that encourages women entrepreneurs to run the downstream activities. This factor's items include 'the need of entrepreneurs to fulfill the dream of having their own business and through the downstream activities that are carried out, women entrepreneurs are able to gain the experience and learn how to be responsible in running a business'. In addition, the study also found that self-control and psychological support factor might also encourage the women to participate in the activities. The items related to this factor include 'not to give up, have support from friends and family and proud to be an entrepreneur'.
\end{abstract}

Keywords: the motivational factors, women entrepreneurs, downstream activities, structural equation modeling (SEM), FELDA

\section{Introduction}

Downstream activity is defined as an extended industrial activity or manufacturing that utilizes raw materials or in-process goods that go through several steps of processing before ended up as consumer goods. Downstream activities exist when there is an opportunity for improvement in an output's value added, i.e. if the said output will become an input to the production of output of higher value. For example, outputs of agricultural, fishery and livestocks that are processed to become other products. Downstream activities involve processing activities and innovation; and are utilized in the manufacturing or service sector.

Downstream activities are among the activities undertake to improve the standard of living especially among the women, may they live in the city or rural areas. The participation of women in downstream activities starts in 
small scale and for own usage. Under the 'barter' system, if there is excess in production, then the said excess will be traded with other goods. When currency was introduced, they started to market the excess products to generate income. In other words, downstream activities provide the opportunity for women to increase their income, may it be as main or supplemental income.

Past societies perceived women as better suited for homes and looked down upon women's capabilities. However, this has since changed. The Malay community is more open-minded now. This can be seen with the presence of bumiputera women in social activities and their participation in challenging occupations. Nowadays, women are also seriously involved in the entrepreneurial field. Although women entrepreneurs play a major role in economic growth and development worldwide, their role has been neglected in dicussions around the concept of entrepreneurial progress, which has traditionally been associated with men (Evelyn et al, 2014).

Studies focusing on women's participation in downstream activities are usually on factors that motivate them to be involved in the said field. According to Zaidatol (2004), there are three factors which influence their participation, namely external, self and motivational factors. External factor encompasses the aspects of support from family and government, unemployment, business exposure and friend's influence. Motivational factors encompasses the desire to increase income, to gain freedom, for the respect, business opportunity and believe that business able to bring growth in their lives. Meanwhile, the self factor is related to the aspects of sufficient training, skills and knowledge in participating in this field. Entrepreneurs believe that they are capable in handling all the challenges in the business world as they possessed all the said three factors.

Nonetheless, the main factor that motivates women entrepreneurs to be involved in downstream activities are related to family, that is to increase family income or as main source of income for women entrepreneurs who are also single mothers. According to Shane (2003), family size affects the participation in downstream activities; and this opinion is suppported by Salman (2009) who stated that in Pakistan, women with one or two children are more interested to participate in businesses to generate family income. On the other hand, Allen et al. (2008) and Lawal et al. (2009) opined that women with large family, those with more than five family members are found to be more interested in becoming entrepreneurs.

Besides that, the factors of self or attitude, training as well as the education of an entrepreneur are the main determinants in improving entrepreneurial skills and reduce the risk of business failure. According to the entrepreneurial development model developed by Rohayu et al. (2012), the success of an entrepreneur is also influenced by background and cultural factors. The Malaysian government has also played its role through the various assistance and supports provided to entrepreneurs especially the women entrepreneurs to develop and improve their potential. Thus, the government has came out with various strategies such as developing the small and medium enterprises (SME) and village/cottage industry to encourage the participation of bumiputera entrepreneurs especially in industries that are based on local raw materials. The focus of this paper is to observe the motivational factors that influence the participation of women entrereneurs in downstream activities through a study done on women entrepreneurs at FELDA. The main downstream activities undertaken by the respondents at study locations include small scale business $(37.0 \%)$, tailoring $(11.3 \%)$, processed food or traditional cakes $(20.5 \%)$, other businesses $(19.9 \%)$, handicrafts $(5.5 \%)$, livestocks $(2.4 \%)$, agriculture $(1.7 \%)$, beauty centres $(1.0 \%)$ and hair saloons $(0.7 \%)$.

\section{Review of Past Studies}

Various studies related to entrepreneurial development had been conducted. The most disccussed theories are of economics, psychological and sociological theories. Many researchers had studied these motivational theories and presented various critics on those theories.

Kwabena (2011) had studied motivational theories such as of economic, sociological and anthropological theories, as well as opportunity-based theory and resource-based theory based on emphirical evidences. Even though each of the theories has its own critics, these theories are still relevant in the study of entrepreneurialship.

Moreover, a study was also conducted by Hafiz et al. (2012) on entreprenuers' psychological and non-psychological factors that affect the orientation of entrepreneurialship in Pakistan. The psychological factors evaluated were the need for success, locus of control, tolerence towards uncertainty and entrepreneurial instict. Meanwhile, non-psychological factors are roles of education, multiplicity of skills, formal/social relations and informal/personal relations. The study found that psychological and non-psychological factors are significant and positive in affecting entrepreneurial orientation. Entrepreneurs need to possess the desire for high achievement, high locus of control, high tolerence towards uncertainty and powerful instinct. Their study also found that the most successful entrepreneurs are those with families of business background, and source of capital are from 
family and friends. Meanwhile, education and difference in level of skills are among the important factors in the development of entrepreneurial culture.

A study conducted by Kavita R.N and Santhi (2013) attempted to observe the extent of environmental, personality and motivational factors in influencing women entrepreneurs and non-entrepreneurs in participating in downstream activities in Malaysia. Those three factors are found to be significant in influencing the entrepreneurs in participating in downstream activities. The environmental factors are consisted of psychological support, benefits from environment and situation of previous work place. Past studies by Silver (1983) and Wilken (1987) found that the entrepreneurs' psychological support is lower than non-entrepreneur due to the pressureof being from poor family. There are nine personality factors which influence entrepreneurs namely skill, emotional stability, alertness, abstractness, more private, open to change, perfectionist, more stress and lack of confidence. This study results correspond with study results of De Vries (1996) which disclosed that entrepreneurs need control, doubt, desire to be appreciated and need to undergo the primitive defence mechanism. Meanwhile, Kamisan and Nek Kamal (2009) opined that personality and socioeconomic factors affect women entrepreneurs in Malaysia. The study found that technology and information are the main factors influencing the participation of women entrepenuers, followed by personal traits such as work ethics and managerial value.

\section{Data and Methodology}

This study is based on survey method; and was conducted by distributing survey questionnaires at the FELDA land schemes. The population of study is limited to the women entrepenuers of FELDA. All the questionnaires distributed to respondents were completely answered. This means that the confidence level is 100 percent. There was a total of 292 respondents from 10 FELDA land schemes, namely of FELDA Raja Alias, FELDA Jengka, FELDA Terengganu, FELDA Jelai, FELDA Chini, FELDA Palong, FELDA Pasak, FELDA Air Tawar, FELDA Tenang and FELDA Palong Timur.

This study utilized questionnaires as study instrument in identifying the motivational factors that encourage the participation of women in downstream activities at the FELDA land scheme. This study was developed using the 5-point Likert scale to measure each item of factors that motivates women entrepreneurs in participating in the downstream activities. Further, the data will be analysed by utilizing the Statistical Packages For Social Science (SPSS) 10.0 program to obtain frequencies and percentages. The SPSS was also utilised as to conduct factor analysis on each of the items as well as reliability tests on each of the constructs developed. Besides that, this study also utilized SPSS AMOS version 5.

The analysis of study was conducted by utilizing the statistical analysis technique, namely the Structural Equation Modelling (SEM). The SEM model is used to observe the relationship of the items which motivates the women entrepreneurs to participate in downstream activities. For the model to be the best, several indicators were utilised as permissable limit to check for the fitness of the said measurement model. The analysis depended on fitness indices such as CMIN/df, CFI, TLI, IFI, RFI, NFI, and RMSEA.

\section{The Results}

Table 1 depicts the demographic information of women entrepreneurs; encompassing information related to age, marital status, number of household members, education level and generation. Study results showed that most respondents were in the age category of 22 to 60 years old. This is because at these ages productivity is high in order to undertake the downstream activities. Study also discovered that 88.7 percent of the respondents were married and 45.9 percent of the respondents were with household of more than 6 persons. In terms of education level, 46.9 percent of the respondents were with SPM or its equivalent, 26.4 percent of respondents received their education up to primary school, while respondents with certificates/Diplomas/Degrees and more, made up only 9.9 percent of respondents. This shows that majority of the women entrepreneurs do not have high level of education. According to a study conducted by Dolinsky and Caputo (1993), the level of education determines the involvement of women in entrepreneurialship and in sustaining inthe said profession. Women with lesser education are most likely to face financial or capital problems that will limit the growth of their business.

Model that tests the factors' relationship in motivating entrepenuers to participate in downstream activities was analysed by the Factor Analysis (EFA) and Confirmatory Factor Analysis(CFA). In order to conduct the analyses, SPSS V21 was utilized to measure the reliability of each item, as well as the Cronbach alpha for each construct that wasdeveloped. The closer the value of the Cronbach alpha to 1, the more reliable it is. If the value of Cronbach alpha is less than 0.60, then it can be assumed that the instrument used in the study has low reliability. According to Uma Sekaran (1992), good and acceptable level of reliability is when Cronbach alpha value is more than 0.70 . Thus as recommended by Nunally (1978), contructs with Cronbach alpha value of lesser than 0.70 will be dropped in the next analysis. 
Table 2 depicts the results of factor analysis conducted on 20 items of motivational factors where 6 constructs were established. Based on the evaluation of factor loading and Cronbach alpha, 6 motivational factor contructs were selected. The constructs consisted of the desire for success, locus of control and psychological support, achievement and recognition oriented, as well as motivated towards business. Table 3 depicts the results of factor loading and reliability. Based on the said table, generally the factor loading for all the 15 items are high. The lowest factor loading is 0.508 as shown by item F10, i.e. receive highdemand for product produced. Meanwhile, the highest factor loading is at 0.866 for item F03, i.e. gaining experience from business. According to Comrey and Lee (1992) and Distefano and Hess (2005), factor loading with a value of 0.6 is very good, while 0.70 and above as excellent as latent construct is higher than error variance.

Table 1. Respondents' demographic

\begin{tabular}{lcc}
\hline Respondent Demographic & Frequency & Percentage \\
\hline Marital Status & & \\
Single/ unmarried & 9 & 3.1 \\
Widow/Divorce & 24 & 8.2 \\
Married & 259 & 88.7 \\
\hline Age & & \\
18-21 year old & 2 & 0.7 \\
22-30 year old & 46 & 15.8 \\
31-40 year old & 73 & 25.0 \\
41-50 year old & 62 & 21.2 \\
51-60 year old & 83 & 28.4 \\
More than 60 year old & 26 & 8.9 \\
\hline No of household members & & \\
1-2 persons & 18 & 6.2 \\
2-4 persons & 78 & 26.7 \\
4-5 persons & 62 & 21.2 \\
More than 6 persons & 134 & 45.9 \\
\hline Education Level & & \\
None & 9 & 3.1 \\
Primary school & 77 & 26.4 \\
SRP/PMR or equivalent & 25 & 8.6 \\
SPM or equivalent & 137 & 46.9 \\
STPM or equivalent & 15 & 5.1 \\
Certificate/Diploma/ Degree or equivalent & 29 & 9.9 \\
\hline
\end{tabular}

Table 2. Factor analysis

\begin{tabular}{lcccccc}
\hline \multicolumn{1}{c}{ Construct } & \multicolumn{7}{c}{ Factor Loading } \\
& 1 & 2 & 3 & 4 & 5 & 6 \\
\hline Taking advantage of good economy (F1) & .270 & .169 & .171 & .391 & .287 & .164 \\
Fulfilling a dream (F2) & .220 & .043 & .211 & $\mathbf{. 8 2 6}$ & .148 & .068 \\
Gain experience (F3) & .136 & .088 & .079 & $\mathbf{. 8 6 6}$ & .180 & .086 \\
Learn to be responsible (F4) & .172 & .172 & -.013 & $\mathbf{. 6 2 0}$ & -.040 & .529 \\
Support from friends and family (F5) & .160 & .105 & .037 & .209 & .171 & $\mathbf{. 7 6 3}$ \\
Provide comfortable life to family (F6) & .110 & -.077 & .366 & .069 & .047 & $\mathbf{. 7 6 6}$ \\
Not discouraged/give up easily (F7) & .215 & .058 & $\mathbf{. 7 6 2}$ & -.035 & .077 & .380 \\
High self-confidence (F8) & .186 & .192 & $\mathbf{. 7 9 8}$ & .130 & .199 & .101 \\
Proud to be an entrepreneur(F9) & .100 & .042 & $\mathbf{. 8 1 3}$ & .218 & .005 & -.008 \\
Receive high demand (F10) & .182 & $\mathbf{. 5 0 8}$ & .305 & .010 & -.044 & -.295 \\
Community acceptance (F11) & .158 & $\mathbf{. 8 0 4}$ & .109 & -.030 & .019 & .063 \\
\hline
\end{tabular}


Measuring own capability (F12)

Practice of business knowledge (F13)

Customer relationship (F14)

Happiness and quality living (F15)

Business opportunity (F16)

Lucrative income (F17)

Like to be involved in business(F18)

Freedom in decision-making (F19)

Life changing (F20)

Extraction Method: Principal Component Analysis. Rotation Method: Varimax with Kaiser Normalization.

a. Rotation converged in 6 iterations.

Table 3. Results of factor analysis and reliability test

\begin{tabular}{|c|c|c|c|}
\hline \multicolumn{2}{|c|}{ Motivational Item } & $\begin{array}{l}\text { Factor } \\
\text { loading }\end{array}$ & Reliability \\
\hline \multicolumn{4}{|c|}{ Desire for success } \\
\hline $\mathrm{F} 02$ & Fulfilling dream to own business & 0.826 & \multirow{3}{*}{0.813} \\
\hline F03 & Gain experience from business & 0.866 & \\
\hline F04 & Learn to be responsible & 0.620 & \\
\hline \multicolumn{4}{|c|}{ Self-control \& Psychological support } \\
\hline F07 & Someone who is not discouraged/give up easily & 0.762 & \multirow{3}{*}{0.814} \\
\hline F08 & Gain support from friends and family & 0.798 & \\
\hline F09 & Proud to be an entrepreneur & 0.813 & \\
\hline \multicolumn{4}{|c|}{ Achivement and Recognition Oriented } \\
\hline F10 & Receive high demand for product & 0.508 & \multirow{4}{*}{0.736} \\
\hline F11 & Good community acceptance to entrepreneur & 0.804 & \\
\hline F12 & $\begin{array}{l}\text { Able to measure one's capability in managing the } \\
\text { business }\end{array}$ & 0.819 & \\
\hline F13 & $\begin{array}{l}\text { Practice the business related knowledge to improve } \\
\text { in business }\end{array}$ & 0.722 & \\
\hline \multicolumn{4}{|c|}{ Motivated towards Business } \\
\hline F16 & $\begin{array}{l}\text { Opportunity to be involved in business and the said } \\
\text { business suits one's self }\end{array}$ & 0.561 & \multirow{5}{*}{0.810} \\
\hline F17 & Better income if involve in business & 0.745 & \\
\hline F18 & Like to be involved in business & 0.729 & \\
\hline F19 & Free to make business related decision & 0.735 & \\
\hline F20 & $\begin{array}{l}\text { Involve in business due to desire to make changes in } \\
\text { life }\end{array}$ & 0.728 & \\
\hline
\end{tabular}

Note: Extraction Method: Principal Component Analysis. Rotation Method: Varimax with Kaiser Normalization. a. Rotation converged in 6 iterations.

Results from the Exploratory factor analysis show that the value of KMO(Kaiser-Meyer-Olkin) is 0.804 with Chi-Square (Bartlett's Test of Sphericity) value of 2491.116. The KMO value obtained from this analysis exceeds 0.50 as recommended by Hair et al. (1998). 
Further, the confirmatory factor analysis was conducted by utilizing the statistical analysis technique of structural equation modelling (SEM). The SEM model was utilized to determine the strength of the entrepreneurs' motivational factor in participating in the downstream activities, refer Figure 1. In order for SEM to be the best model utilized, several indicators were employed as permissable limit. According to Shairil \& Hasnah (2013), in order to check for the fitness of the measurement model, the analyses depend on the fit indices such asCMIN/df, CFI, TLI, IFI, RFI, NFI, and RMSEA.

Table 4 indicates the values of Squared Multiple Correlation (SMC) which is a detailed evaluation on determining the reliability of 15 items in measuring 4 contructs of motivational factors; namely 'desire for success', 'locus of control and psychological support', 'achievement and recognition oriented', and 'motivated towards business'. Results from the said Table 4 show that the SMC values are between 0.125 to 0.799 . There are 5 items which indicate high SMC value, namely F08 at $0.799, \mathrm{~F} 03$ at $0.701, \mathrm{~F} 02$ at $0.697, \mathrm{~F} 13$ at 0.637 and F12 at 0.620 . These show that the variance extracted by item F08 is 79.9 percent at self-control and psychological contructs. Item F03 indicates the extracted variance is 70.1 percent at the desire for success construct. According to Arbuckle (1997), SMC of above 0.30 is the acceptable indication to an item or indicator to measure related construct. In this model, item F10 is not accepted to measure the construct due to its SMC value is lesser than 0.30 .

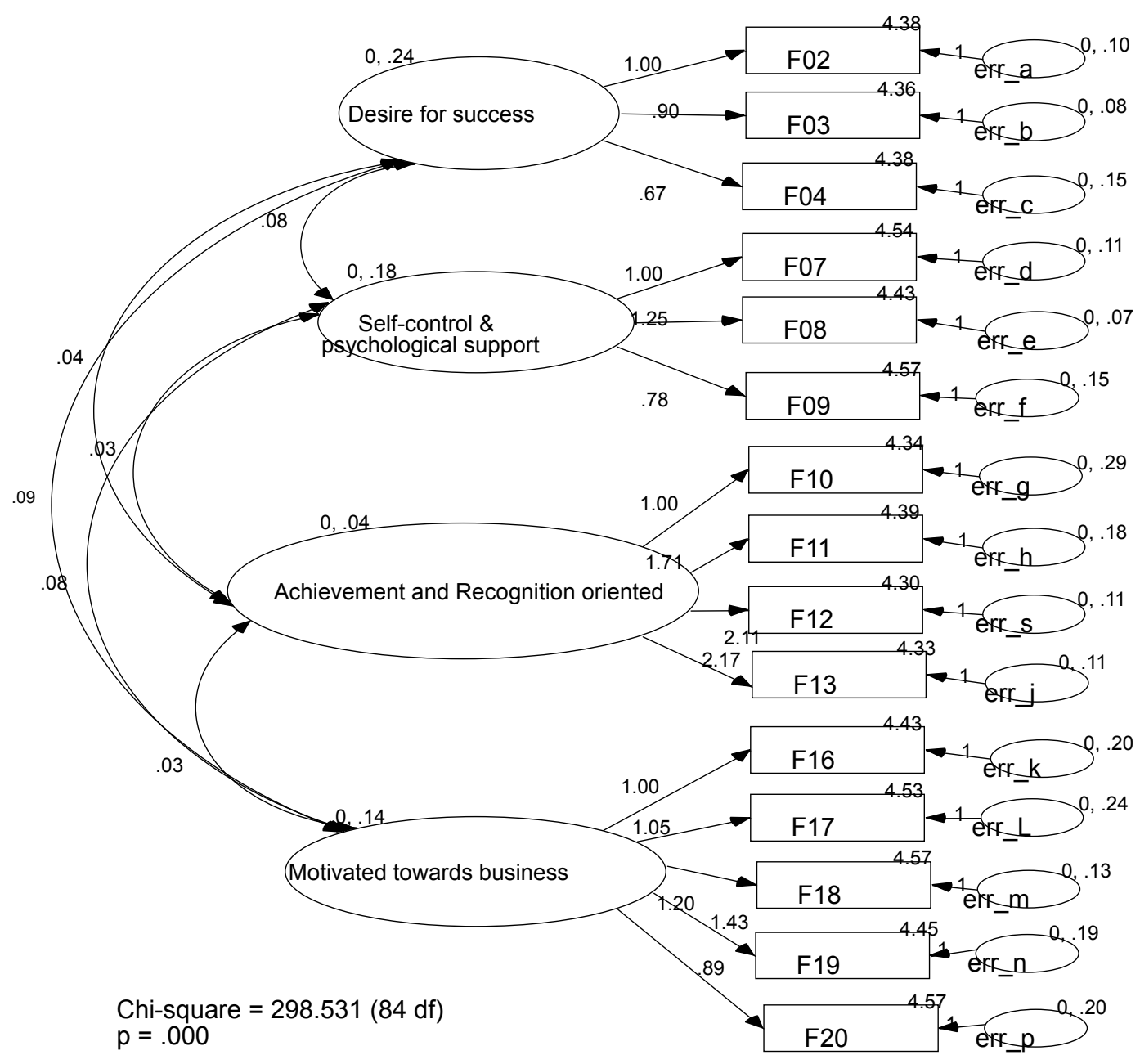

Figure 1. Results of structural equation model on motivational factors in participating in downstream activities 
Table 4. Squared Multiple Correlations (SMC)

\begin{tabular}{lcl}
\hline \multicolumn{1}{c}{ Factor } & Motivational Item & SMC \\
\hline \multirow{3}{*}{ Desire for success } & F02 & 0.697 \\
& F03 & 0.701 \\
& F04 & 0.419 \\
\hline \multirow{2}{*}{ Self-control } & F07 & 0.606 \\
psychological support & F08 & 0.799 \\
& F09 & 0.411 \\
\hline \multirow{2}{*}{ Achievement and } & F10 & 0.125 \\
recognition oriented & F11 & 0.400 \\
& F12 & 0.620 \\
\hline \multirow{2}{*}{ Motivated } & F13 & 0.637 \\
business & F16 & 0.406 \\
& F17 & 0.386 \\
& F18 & 0.595 \\
& F19 & 0.598 \\
\hline
\end{tabular}

Results indicate that encouragement or motivational item in the desire for success construct shows higher SMC value. This construct is consisted of 3 motivational items that encourage an entrepreneur in participating in downstream activities: i) to fulfil the dream to run own business, ii) women entrepreneurs able to gain experience, and iii) learn to be responsible. In order to fulfil such dreams, they have motivated the women in pursuing the downstream activities. According to McClelland (1961), one with the need to greater success will be encouraged to set a goal and toil towards that goal through skills and self capability. Besides that, the spirit of the entrepenuer in gaining experience from the business will encourage the entrepeneur to undertake downstream activities especially from the aspects of management, re-organization, production, marketing, sales and others. Based on the psychological theory by McClelland, those with the need for greater achievement will desire for instant feedback in order to evaluate their performance, as to whether to change their actions or not. Nonetheless, Chell et al. (1991) stated that there is a culture where failure is deemed as a positive experience in educating the entrepeneurs. The women entrepreneurs are encouraged to participate in the downstream activities due to their desire to learn to be responsible. According to McClelland, individuals with the desire for success are those who prefer to take the responsibility towards achieving certain goal on their own accord. Women entrepreneurs are responsible towards the direction of their business and decision-making in managing as well as in handling of problems.

Besides that, the self-control and psychological contruct is the second construct that has high SMC value where it also encourages the women entrpenuers to participate in downstream activities. This construct encompasses of 3 motivational factors: i) not giving up easily, ii) encouragement from friends, and iii) proud to be an entrepreneur. Entrepreneur is someone who does not give up easily and works hard to achieve the desired goal. Study found that the encouragement from friends and family is psychological support that pushes the enrepreneur to participate in downstream activities and this finding is in accordance to the finding of Shapero \& Sokol (1982). However, this finding contradicted the finding of Kavita and Santhi (2013) who found psychological support to entrepreneurs is low. Entrepreneurs are also motivated to participate in the downstream activities due to proud to be an entrepreneur. According to Rotter (1966), entrepreneurs are individuals with high self-confidence, independent, and able to control themselves.

The correllations among the proposed indicators depicted in Table 5 are to observe the interaction between the entrepreneurs and the factors that motivate the women in participating in the downstream activities at FELDA. Each of the developed factors has been analysed to show corellation between the factors through AMOS. Results in Table 5 show values of between 0.352 and 0.543 . The corellation between self-control and psychological support, and motivated towards business is at 54.3 percent. Meanwhile, the correlation between the desire for success, and motivated towards business is at 51.1 percent. The correlation between these two indicators indicate 
that self-control and psychological support as well as the desire for success will respond to the motivation towards business among the respondents. The results of this study also depict the presence of weak relationship between factors, namely between self-control and psychological support, and achievement and recognition oriented at 35.2 percent.

Table 5. Correlation among motivational factors

\begin{tabular}{llllc}
\hline & & & Estimate \\
\hline Self-control \& psychological & & Achievement \&recognition oriented & .352 \\
support & & Achievement\&recognition oriented & .359 \\
Desire for success & $\leftrightarrow$ & Self-control \& psychological support & .392 \\
Desire for success & $\leftrightarrow$ & Selo & .511 \\
Motivated towards business & $\leftrightarrow$ & Desire for success & .543 \\
Motivated towards business & $\leftrightarrow$ & Self-control \& psychological support & .383 \\
Motivated towards business & $\leftrightarrow$ & Achievement \&recognition oriented & \\
\hline
\end{tabular}

Besides that, the AMOS analysis is also able to identify presence of goodness of fitexplained in the Model of Fit. According to Arbuckle (2007), the method of analysis forthe model of fit is the CMIN/DF, known as relative chi-square. Even though there is specific value, Kline (1998) stated that the ratio should be less than 3. However, there is also determination made where the ratio should be less than 5. Chi-square is used to measure the difference between the developed model and utilised data. This study obtained a CMIN/DF value of 3.553, lesser than 5 (refer to Table 6).

Table 6. Model of fit for structural equation model

\begin{tabular}{lccccccc}
\hline Model & CMIN/DF & NFI & RFI & IFI & TLI & CFI & RMSEA \\
\hline Error Model & 3.554 & 0.837 & 0.797 & 0.878 & 0.845 & 0.876 & 0.094 \\
Saturated model & & 1.000 & & 1.000 & & 1.000 & \\
Unrestricted model & 17.488 & .000 & .000 & .000 & .000 & .000 & 0.238 \\
\hline
\end{tabular}

NFI or Normed Fit Index depicts quality of the model as compared to the estimated model. The value obtained for the NFI is 0.837. Garson (2008) recommended that the NFI value should be between 0.90 and 0.95 . Meanwhile, RFI refers to the Relative Fit Index, is not guaranteed to vary from 0 to 1 ; but RFI approaching 1 indicates that the model is good where the result obtained is 0.797. IFI is the Incremental Fit Index which also, is not guaranteed to vary from 0 to 1 ; but IFI which approaches 1 indicates a good model where result obtained is 0.878 . TLI or Tucker Lewis Index which approaches 1 indicates good fit, where result obtained is 0.845 . Meanwhile CFI approaches 1 indicates good fit where the result obtained is 0.876 . The RMSEA value obtained for this study is 0.094 . Thus, it can be concluded that the developed model is compatible with the variables.

\section{Conclusions}

The objective of the study is find out the motivational factors that encourage most the participation of women in business activities. This study concludes that the 'basic motivational factor' is the most important factor that encourages entrepreneurs to participate in the downstream activities. This can be observed from the motivation items in the 'desire for success' construct, namely to fulfil dream, gain experience from business as well as the desire to learn accepting responsibility. The desire for succes contruct shows higher SMC value. According to McClelland, through the Thematic Apperception Test (TAT) conducted, it is found that an individual with the need for great success does possess all the three personality traits. Analysis by AMOS is also supports the SMC result which shows high percentage of correlation. We thus can conclude that this finding is helping us to achieve the objective of the study. 
Besides that, this study also discovered that the construct of self-control and psychological support also encourages women entrepreneurs to participate in downstream activities. This construct is consisted of 3 motivational factors, namely does not give up easily, encouragement from friends and family as well as proud to be an entrepreneur. It can be observed that the motivational items that influence the entrepreneurs in participating in downstream activities are of entrepreneurs' psychological or personality traits.

In view that the psychological factor is found to have more influence on the entrepreneurs, this study recommends that more courses and development programs that influence and motivate individuals towards achieving their goals through changes, especially through the way of thinking, mentality and individual traits, be conducted. This is because according to McClelland, entrepreneurs are not born but are made or molded as psychological attributes can be learned or changed.

Moreover, the entrepreneurial traits can be cultivated since school, where it is the best place to encourage the students, and for them to learn about business and entrepreneurialship. The establishment of co-operative at schools is hoped to initiate the entrepreneurialship culture where it may be able to instill the traits of an entrepreneur and provide the basic knowledge of entrepreneurialship.

\section{Acknowledgements}

This research was supported by the National University of Malaysia through the MPOB Endownment Research Grant (MPOB-UKM-2013-006).

\section{References}

Allen, I. E., Elam, A., Langowitz, N., \& Dean, M. (2008). 2007 Global Entrepreneurship Monitor Report o Women and Entrepreneurship. Babson College: The Centre for Women's Leadership.

Arbuckle, J. L. (1997). AMOS Users' Guide: Version 3.6. Chicago. SPSS.

Arbuckle, J. L. (2007). Amos 16.0 User's Guide. Chicago: SPSS.

Comrey, \& Lee. (1992). Second edition. L. United States: Erlbaum Associates.

DiStefano, C., \& Hess, B. (2005). Using Confirmatory Factor Analysis for Construct Validation: An Eempirical Review. Journal of Psychoeducational Assessment, 23, 225-241. http://dx.doi.org/10.1177/073428290 502300303

De Vries, M. F. K. (1996). The Anatomy of the Entrepreneur: Clinical Observations. Human Relations, 49(7), 853-883. http://dx.doi.org/10.1177/001872679604900701

Derera, E., Chitakunye, P., \& O'Neill, C. (2014). The Impact of Gender on Start-up Capital: A Case of Women Entrepreneurs in South Africa. Journal of Entrepreneurship, 23, 95-114. New Delhi: SAGE Publications. http://dx.doi.org/10.1177/0971355713513355

Kline, R. B. (1998). Principles and Practice of Structural Equation Modeling. New York. Guilford Press.

Dolinsky, A. L., \& Caputo, R. K. (1993). The Effects of Education on Business Ownership: A Longitudinal Study on Women. Entrepreneurship: Theory and Practice, 18(1), 43.

Ullah, H., Farooq, M. A., \& Ahmad, Z. M. (2012). A Study of Psychological and Non Psychological Factors of Owner Influencing Entrepreneurial Orientation: Evidence from Khyber Pakhtunkhwa-Pakistan. Journal of Management Science and Engineering, 6, 44-55

Hair, J. F., Anderson, R. E., Tatham, R. L., \& Black, W. C. (1998). Multivariate Data Analysis. Upper Saddle River, NewJersey. Prentice Hall.

Gadar, K., \& Yunus, N. K. Y. (2009). The Influence of Personality And Socio-Economic Factors on Female Entrepreneurship Motivations in Malaysia. International Review of Business Research Papers, 5(1), 149-162.

Raman, K., Anantharaman, R. N., \& Ramanathan, S. (2013). Environmental, Personality and Motivational Factors: A Comparison Study between Women Entrepreneurs and Women Non -Entrepreneurs in Malaysia. International Journal of Business and Management, 8(13), 15-23. http://dx.doi.org/10.5539/ijbm.v8n13p15

Lawal, J. O., Omonona, B. T., Ajani, O. I. Y., \& Oni, O. A. (2009). Effects of Social Capital on Credit Access among Cocoa Farming Households in Osun State, Nigeria. Agricultural Journal, 4(4), 184-191. Retrieved from http://docsdrive.com/pdfs/medwelljournals/aj/2009/184-191.pdf

McClelland, D. C. (1961). The Achieving Society. NJ: Van Nostrand, Princeton. 
Nunnally, J. C. (1978). Psychometric Theory. New York: McGraw-Hill.

Roddin, R. (2012). Pendekatan Model Baru Pembangunan Usahawan Wanita Luar Bandar Bagi Tujuan Pembasmian Kemiskinan.

Rotter, J. B. (1966). Generalized Expectancies for Internal Versus External Locus Control of Reinforcement. Psychological Monographs: General and Applied, 609(80), 1-28. http://dx.doi.org/10.1037/h0092976

Salman, A. (2009). How to Start a Business: A Guide for Women. Pakistan: Centre for International PrivateEnterprise, Institute of National Endowment for Democracy, affiliate of the USA Chamber of Commerce.

Taasim, S. I., \& Ali, H. (2013). Penerimaan Pengguna Terhadap Kaedah Pembayaran Elektronik. Jurnal Ekonomi Malaysia, 47, 3-12.

Silver, D. A. (1983). The Entrepreneurial Life Theories and Empirical Research: A Summary Review of the Literature. European Journal of Business and Management, 3(6), 1-8. Retrieved from file:///C:/Documents\% 20and\%20Settings/UKM/My\%20Documents/Downloads/531-1359-1-SM.pdf.

Shane, S. (2003). A general Theory of Entrepreneurship: The Individual-Opportunity Nexus. UK: Edward Elgar. http://dx.doi.org/10.4337/9781781007990

Shapero, A., \& Sokol, L. (1982). Social Dimensions of Entrepreneurship. In C. A. Kent, D. L. Sexton, \& K. H. Vesper (Eds.), Encyclopaedia of Entrepreneurship. Prentice Hall. Englewood Cliffs, New Jersey.

Wilkens, J. (1987). Her Own Business: Success Secrets of Entrepreneurial Women. US: McGraw Hill.

Noor, Z. M., Kasimin, H., Aman, A., \& Sahari, N. (2011). Evaluating End-User Satisfaction with an E-Goverment Service Electronic Labor Exchange (ELX). Jurnal Ekonomi Malaysia, 45, 11-20.

\section{Copyrights}

Copyright for this article is retained by the author(s), with first publication rights granted to the journal.

This is an open-access article distributed under the terms and conditions of the Creative Commons Attribution license (http://creativecommons.org/licenses/by/3.0/). 